\title{
Baseline Sensitivity of Botrytis cinerea to the Succinate Dehydrogenase Inhibitor Isopyrazam and Efficacy of this Fungicide
}

Yingying Song, College of Plant Protection, Shandong Agricultural University, Shandong Provincial Key Laboratory for Biology of Vegetable Diseases and Insect Pests, Tai'an, Shandong 271018, P.R. China; Zhengqun Zhang, College of Horticulture Science and Engineering, Shandong Agricultural University, Tai' an 271018, P.R. China; and Lele Chen, Leiming He, Hongbao Lu, Yupeng Ren, Wei Mu, and Feng Liu, College of Plant Protection, Shandong Agricultural University, Shandong Provincial Key Laboratory for Biology of Vegetable Diseases and Insect Pests

\begin{abstract}
Song, Y., Zhang, Z., Chen, L., He, L., Lu, H., Ren, Y., Mu, W., and Liu, F. 2016. Baseline sensitivity of Botrytis cinerea to the succinate dehydrogenase inhibitor isopyrazam and efficacy of this fungicide. Plant Dis. 100:1314-1320.

Isopyrazam is a new broad-spectrum, foliar-absorbed and -translocated succinate dehydrogenase inhibitor fungicide. In this study, 159 Botrytis cinerea isolates collected from different geographical regions of Shandong Province of China were characterized for baseline sensitivity to isopyrazam. Furthermore, the protective and curative activity of isopyrazam on strawberry fruit and the control efficacy in the field were also determined. In contrast to its mycelial growth, the spore germination of $\mathrm{B}$. cinerea was inhibited completely by lower concentrations of isopyrazam, about $1 \mu \mathrm{g} \mathrm{ml}^{-1}$ on yeast-peptone-acetate medium. Frequency distributions of isopyrazam $50 \%$ effective concentration $\left(\mathrm{EC}_{50}\right)$ values were

unimodal curves, with mean $\mathrm{EC}_{50}$ values of $0.07 \pm 0.04$ (standard deviation) and $0.68 \pm 0.36 \mu \mathrm{g} \mathrm{ml}^{-1}$ for the inhibition of spore germination and mycelial growth, respectively. In addition, there was no positive multiple resistance between isopyrazam and other classes of botryticides such as diethofencarb, iprodione, pyrimethanil, or SYP-Z048. In field trials conducted during 2014 and 2015, isopyrazam used at a concentration of active ingredient at 150 and $200 \mathrm{~g} \mathrm{ha}^{-1}$ provided a control efficacy ranging from 76.7 to $87.8 \%$ on leaves and from 81.5 to $90.7 \%$ on fruit These results suggest that isopyrazam has the potential to play an important role in the management of gray mold.
\end{abstract}

Botrytis cinerea Pers. (teleomorph Botryotinia fuckeliana), the causal agent of gray mold, is a destructive, necrotrophic plant pathogen with a host range of more than 200 plant species (Elad et al. 2004). Hosts include economically important crops such as apple, strawberry, cucumber, and rose (Jarvis 1977; Williamson et al. 2007; Yin et al. 2011). Botrytis cinerea infects flowers but is more damaging to fruit pre- and postharvest (Amiri et al. 2013). Conidia are dispersed by insects, air currents, and water droplets (Kerssies 1993).

Because resistant cultivars have not yet been developed for major crops, the application of fungicides remains the major approach for managing $B$. cinerea. Multiple categories of fungicides with different modes of action against gray mold are employed, including dicarboximides (e.g., procymidone and iprodione), benzimidazoles (e.g., carbendazim), N-phenylcarbamates (e.g., diethofencarb), anilinopyrimidines (e.g., pyrimethanil), succinate dehydrogenase inhibitors (SDHI; e.g., boscalid and fluopyram), sterol biosynthesis inhibitors (e.g., fenhexamid and SYP-Z048), and phenylpyrroles (fludioxonil) (Leroux 2007; Ma et al. 2009; Weber 2011; Yang 2003). However, B. cinerea is at high risk of developing fungicide resistance because of its prolific reproduction and short life cycle (Brent and Hollomon 1998). Selection of resistance to different classes of fungicides is frequently reported in this pathogen (Bardas et al. 2010; Elad et al. 1992; Myresiotis et al. 2007; Rodríguez et al. 2014; Zhang et al. 2009). With the increasing development of resistance to traditional fungicides, the development of alternative fungicides for the successful management of $B$. cinerea is critical.

The target site of SDHI is the succinate ubiquinone oxidoreductase or succinate dehydrogenase (SDH) complex (Keon et al. 1991). The $\mathrm{SDH}$ complex consists of four subunits; that is, a flavoprotein

Corresponding author: F. Liu; E-mail: fliu@sdau.edu.cn

Accepted for publication 2 February 2016.

http://dx.doi.org/10.1094/PDIS-10-15-1220-RE

(C) 2016 The American Phytopathological Society subunit, an iron-sulfur protein subunit (SdhB), and two membraneanchored protein subunits (SdhC and SdhD) (Hägerhäll 1997; Ito et al. 2004). The SDH binding site is composed of the residues in subunits of SdhB, SdhC, and SdhD (Horsefield et al.2006; Yin et al. 2011). The enzyme is located in the inner mitochondrial membrane in eukaryotes or the cytoplasmic membrane of prokaryotes. It is a functional component of both the tricarboxylic cycle and the mitochondrial electron transport chain, and its inhibition leads to a block of the cell energy cycle (Ajigboye et al. 2014; Matsson and Hederstedt 2001). Isopyrazam, an SDHI, was developed and patented by Syngenta Crop Protection in 2008 (Sattler et al. 2010). Isopyrazam is a broadspectrum fungicide (Fraaije et al. 2012; Harp et al. 2011) with the ability to control plant pathogens belonging to species of Ascomycetes and Basidiomycetes. However, to our knowledge, few studies have reported the efficacy of isopyrazam against $B$. cinerea (Shen et al. 2014; Veloukas et al. 2013). Moreover, isopyrazam has not yet been registered for the control of gray mold in China (China Pesticide Information Network 2014). This provides an opportunity to study the baseline sensitivity of $B$. cinerea to isopyrazam prior to its legal use (Russell 2004).

The objectives of this study were to (i) to test the biological activity of isopyrazam against $B$. cinerea in vitro, (ii) establish the baseline sensitivity of $B$. cinerea to isopyrazam via mycelial growth on potato dextrose agar (PDA) media and spore germination on yeast-peptoneacetate (YBA) agar media, (iii) determine the multiple resistance patterns between isopyrazam and other widely used botryticides, (iv) assess the preventative and curative activity of isopyrazam against B. cinerea on strawberry fruit under controlled environmental conditions, and (v) evaluate the efficacy of control provided by isopyrazam against gray mold in the field.

\section{Materials and Methods}

Fungicides. Technical-grade isopyrazam (99\% active ingredient [a.i.]; Sigma-Aldrich), boscalid (97\% a.i.; Shanxi Meibang pesticide Co., Ltd.), fluopyram (96\% a.i.; Bayer CropScience), SYP-Z048 (90\% a.i.; Shenyang Research Institute of Chemical Industry), pyrimethanil (96\% a.i.; Yantai Keda Chemical Co., Ltd.), iprodione (98\% a.i.; Jiangsu Kuaida Agrochemical Co., Ltd.), and diethofencarb (95\% 
a.i.; Jiangsu Lanfeng Biochemical Co., Ltd.) were used to test for biological activity and baseline sensitivity as well as the determination of resistance. Isopyrazam, boscalid, fluopyram, and diethofencarb were dissolved in methanol, while iprodione, pyrimethanil, and SYP-Z048 were dissolved in acetone to prepare stock solutions, which were stored at $4{ }^{\circ} \mathrm{C}$ in the dark. For the evaluation of isopyrazam, fluopyram, and procymidone in vivo, formulated isopyrazam (IZM $125 \mathrm{~g} \mathrm{liter}^{-1} \mathrm{EC}$; Syngenta Crop Protection Ltd.), fluopyram (Luna $41.7 \%$ SC; Bayer CropScience), and procymidone (Sumilex 50\% WP; Sumitomo Chemical Co., Ltd.) were used. The stock solutions were added to cooled molten media (approximately $50^{\circ} \mathrm{C}$ ) after autoclaving.

Fungal isolates. Isolates (total $n=159$ ) of $B$. cinerea were collected in 2010 and 2011 from cucumber $(n=41)$, tomato $(n=39)$, grape $(n=34)$, and strawberry $(n=45)$. The sampling fields were never exposed to any isopyrazam or other SDHI. The 159 isolates were used to determine the baseline sensitivity to isopyrazam. In total, 68 isolates of $B$. cinerea were collected from cucumber, tomato, and strawberry greenhouses in 2014 and 2015. These 68 isolates, exhibiting several levels of sensitivity to boscalid, fluopyram, diethofencarb, iprodione, pyrimethanil, and SYP-Z048 (data not shown), were used to determine the correlation of $B$. cinerea sensitivity to isopyrazam and other botryticides. Single-spore isolates were obtained as described previously (Fernández-Ortuño et al. 2012) in approximately 40 commercial greenhouses in 11 geographic districts, including Jinan, Liaocheng, Tai' an, Zibo, Weifang, Binzhou, Jining, Dezhou, Laiwu, Heze, and Linyi of Shandong Province. For long-term storage, fungal collections were maintained at $-80^{\circ} \mathrm{C}$ in $80 \%$ (vol/vol) glycerol.

Effects on mycelial growth, spore germination, and germ-tube elongation. The effects of isopyrazam on mycelial growth, spore germination, and germ-tube elongation were tested using three $B$. cinerea isolates that were randomly selected from the isolate collection created for the current study. All isolates were sensitive to commonly used botryticides (boscalid, fluopyram, SYP-Z048, pyrimethanil, iprodione, and diethofencarb; data not shown).

The sensitivity to isopyrazam based on mycelial growth was determined according to the methods by Myresiotis et al. (2007) with minor modifications. In brief, PDA medium (containing $200 \mathrm{~g}$ of potato, $20 \mathrm{~g}$ of dextrose, and $20 \mathrm{~g}$ of agar per liter of medium) was routinely supplemented with isopyrazam at final concentrations of $0,0.1,0.5,1$, $5,10,20$, and $40 \mu \mathrm{g} \mathrm{ml}^{-1}$. PDA supplemented with $0.2 \%$ methanol was used as the control. Three replicates were used per concentration. Mycelial plugs ( $5 \mathrm{~mm}$ in diameter) were removed from the margins of 3-day-old colonies of each isolate and placed upside down onto the center of the fungicide-amended or non-fungicide-amended PDA plates. These PDA plates were then incubated at $23^{\circ} \mathrm{C}$ for 3 days in the dark. Each colony diameter (minus the original diameter of the inoculation plug) was measured in two perpendicular directions. All tests were performed three times.

Spore germination and germ-tube elongation were assessed on YBA agar medium (containing $10 \mathrm{~g}$ of yeast extract, $10 \mathrm{~g}$ of Bacto peptone, $20 \mathrm{~g}$ of sodium acetate, and $15 \mathrm{~g}$ of agar per liter of medium), developed by Stammler and Speakman (2006) and modified by Miyamoto et al. (2010). Conidial suspensions for each isolate were prepared in sterile distilled water at a concentration of $1.0 \times$ $10^{5} \mathrm{ml}^{-1}$ according to Amiri et al. (2013), and $0.1 \mathrm{ml}$ of conidial suspension was spread on 9-cm YBA plates that contained isopyrazam at $0,0.01,0.02,0.04,0.06,0.08,0.1,0.2,0.4$, and $0.6 \mu \mathrm{g} \mathrm{ml}^{-1}$. After $24 \mathrm{~h}$ of incubation at $23^{\circ} \mathrm{C}$ in the dark, conidia germination and germtube length were examined under a microscope. Conidia were considered to have germinated when the germ-tube length exceeded half the length of the spore. Germination was quantified by counting 100 conidia per plate for each fungicide concentration tested. The lengths of the germ tubes of 20 to 50 germinated conidia per plate were measured with a micrometer on the lens of the microscope. Three replicate petri dishes were prepared for each isolate and fungicide concentration combination, and all the experiments were performed twice.

Baseline sensitivity to isopyrazam. Measurements of baseline sensitivity to isopyrazam were examined on the 159 isolates of $B$. cinerea collected during 2010 and 2011. Sensitivity assays were based on measurements of mycelial growth and the inhibition of spore germination, as described above. The experiment was performed twice. The fungicide concentration that reduced fungal growth rate by $50 \%$ compared with the control $\left(\mathrm{EC}_{50}\right.$ value) for each isolate was calculated.

Correlation of $B$. cinerea sensitivity to isopyrazam and other botryticides. Sensitivity to isopyrazam, boscalid, fluopyram, diethofencarb, iprodione, pyrimethanil, and SYP-Z048 belonging to several chemical classes was tested for $68 \mathrm{~B}$. cinerea isolates by measuring mycelial growth (Ma et al. 2009; Zhang et al. 2007). Serial concentrations of each fungicide were prepared so that, for each isolate, there was at least one concentration with a percent inhibition below $50 \%$ and at least another concentration with a percent inhibition above $50 \%$. All measurements were performed on PDA, except the sensitivity test for pyrimethanil, which was conducted on a synthetic medium (L-asparagine-based agar medium) (Hammer et al. 1993). For each fungicide, the $\mathrm{EC}_{50}$ value was calculated. There were three replications per concentration and the experiment was repeated two times.

Preventative and curative activity of isopyrazam. The in vivo preventative and curative activity of isopyrazam was evaluated on strawberry fruit ('Camarosa') according to a previously described method (Veloukas and Karaoglanidis 2012), with minor modifications (Amiri et al. 2013). Fruit had never been sprayed with fungicide and were collected at the white-pink stage on the basis of shape and size uniformity from an experimental strawberry greenhouse. The fruit were disinfected by washing with $0.5 \%$ ( $\mathrm{vol} / \mathrm{vol}$ ) sodium hypochlorite solution, then were rinsed with sterile distilled water and subsequently air dried.

Detached fruit were treated with isopyrazam at 50, 100, 150, and $200 \mu \mathrm{g} \mathrm{ml}^{-1}$, with formulated fluopyram and procymidone as reference fungicides applied at doses of 80 and $600 \mu \mathrm{g} \mathrm{ml}^{-1}$, respectively. Control fruit were sprayed with deionized water. Each treatment was sprayed until runoff with a hand-held sprayer (Xinmeir Co. Ltd.) and air dried for $1 \mathrm{~h}$. Treatments were sprayed with fungicide 24,48 , and $96 \mathrm{~h}$ after inoculation (curative treatment) or prior to inoculation (protective treatment).

Fruit were inoculated with a $B$. cinerea isolate (TA-19) that was sensitive to botryticides tested in this study. A conidial suspension $\left(1.0 \times 10^{5} \mathrm{ml}^{-1}\right)$ of the isolate was prepared as described above. Fruit were inoculated by pipetting $40 \mu \mathrm{l}$ of a conidial suspension on two wounds inflicted at the fruit equator with a fine sterile needle. Uninoculated control fruit were added with sterile water. All fruit were incubated in a moist chamber at $20^{\circ} \mathrm{C}$ for 7 days. Disease severity (DS) was then determined by measuring the mean diameters of rotting lesions in two perpendicular directions around each wound. Twenty replicate fruit for each treatment were analyzed, and the experiment was performed twice. The protective and curative control efficacy (CE) was calculated as follows: $\mathrm{CE}=$ [average lesion diameter of control fruit - average lesion diameter of treated fruit)/(average lesion diameter of control fruit)] $\times 100$.

Field trials. Field experiments were performed on cucumber plants ('Xintai Mici') in March 2014 and 2015. The plants were grown following normal agronomic practices in a greenhouse located in Tai'an City in Shandong Province. The six treatments were (i) to (iii) isopyrazam (EC at $125 \mathrm{~g} \mathrm{liter}^{-1}$ ) applied at 100, 150, and $200 \mathrm{~g}$ a.i. $\mathrm{ha}^{-1}$; (iv) fluopyram (SC 41.7\%) applied at $100 \mathrm{~g}$ a.i. $\mathrm{ha}^{-1}$; (v) procymidone (WP 50\%) applied at $600 \mathrm{~g}$ a.i. $\mathrm{ha}^{-1}$; and (vi) a water treatment control. Six treatment groups with four replicates were arranged in a randomized complete block design; each plot size was $15 \mathrm{~m}^{2}(5$ by $3 \mathrm{~m}$ ), with about 60 plants per plot. The application of each treatment began at the onset of naturally occurring disease symptoms. The spray volume was 750 liters $\mathrm{ha}^{-1}$. The sprayer used in the experiment was the universal MATABI-16 knapsack hand sprayer (Goizper S Coop) and the pressure on the sprayer was set to 0.3 $\mathrm{MPa}$. Fungicides were sprayed three times at 7-day intervals.

Five different locations were selected at random in each plot and three plants were selected per location. The DS of 15 plants in each plot was recorded at initial application and 7 days after each fungicide application. Each leaf was scored according to a disease rating scale of 0 to 9 (Standards Press of China 2000), where $0=$ no disease 
and $1=0$ to $5,3=6$ to $10,5=11$ to $15,7=21$ to 40 , and $9=41$ to $100 \%$ of leaves covered with lesions. The numbers of diseased leaves in each score (or diseased fruit) and total leaves (or fruit) were recorded. The disease index on leaves, the disease incidence on fruit, and the $\mathrm{CE}$ were calculated using the following equations: disease index $($ on leaf $)=\left[\sum\right.$ (number of diseased plant leaves in each score $\times$ disease score)/(total plant leaves investigated $\times 9)] \times 100 \%$, disease incidence $($ on fruit $)=[$ (number of diseased fruit $) /($ total fruit investigated) $] \times 100 \%$, and $\mathrm{CE}$ (on leaf or fruit $)=\left[1-\left(\mathrm{D}_{\mathrm{C} 0} \cdot \mathrm{D}_{\mathrm{T} 1}\right) /\left(\mathrm{D}_{\mathrm{C} 1} \cdot\right.\right.$ $\mathrm{D}_{\mathrm{T} 0}$ ) $\times 100 \%$, where $\mathrm{D}_{\mathrm{T} 0}=$ the disease index of leaves (or the disease incidence of fruit) before treatment application, $\mathrm{D}_{\mathrm{T} 1}=$ the disease index of leaves (or the disease incidence of fruit) after treatment application, $\mathrm{D}_{\mathrm{C} 0}=$ the disease index of leaves (or the disease incidence of fruit) of untreated control plants before spraying, and $\mathrm{D}_{\mathrm{C} 1}=$ the disease index of leaves (or the disease incidence of fruit) of untreated control plants after spraying.

Data analyses. All statistical analyses were performed with the SAS statistical software package (version 9.2; SAS Institute). The $\mathrm{EC}_{50}$ values were calculated by performing a regression of the percent relative growth against the $\log _{10}$ fungicide concentration. The sensitivity to isopyrazam was plotted against the sensitivity to boscalid,

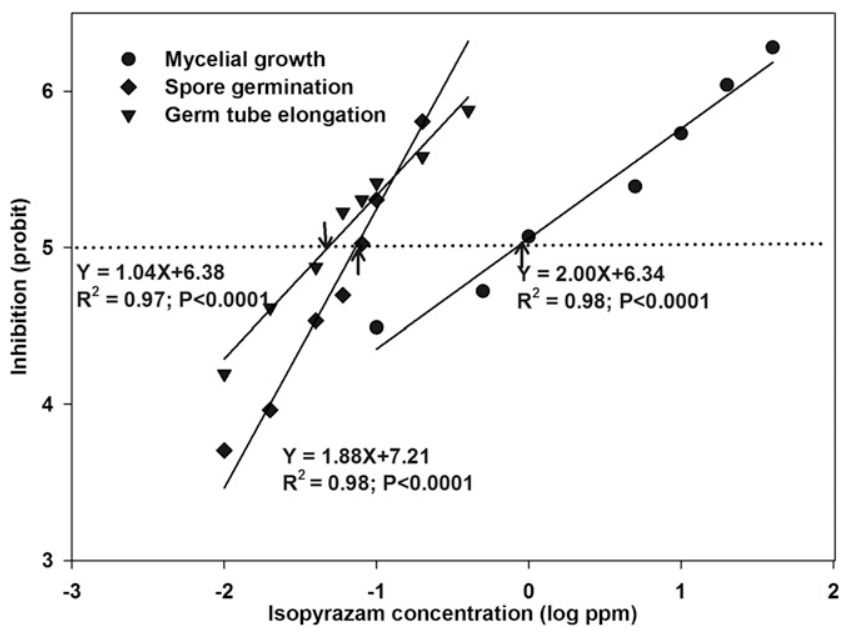

Fig. 1. Inhibition (probit) of mycelial growth, spore germination, and germ-tube elongation for three Botrytis cinerea isolates with isopyrazam at several concentrations. Sensitivity to isopyrazam on mycelial growth was determine on potato dextrose agar media, and spore germination and germ-tube elongation were assessed on yeast-peptone-acetate media.

Table 1. Baseline sensitivity of Botrytis cinerea isolates obtained from four crops to isopyrazam ${ }^{\mathrm{x}}$

\begin{tabular}{|c|c|c|c|c|c|c|c|}
\hline \multirow[b]{3}{*}{ Crop } & \multirow[b]{3}{*}{$N^{\mathbf{z}}$} & \multicolumn{6}{|c|}{$\mathbf{E C}_{\mathbf{5 0}}$ for inhibition of ${ }^{\mathrm{y}}$} \\
\hline & & \multicolumn{3}{|c|}{$\begin{array}{l}\text { Mycelial growth } \\
\left(\mu \mathrm{g} \mathrm{ml}^{-1}\right)\end{array}$} & \multicolumn{3}{|c|}{$\begin{array}{c}\text { Spore germination } \\
\left(\mu \mathrm{g} \mathrm{ml}^{-1}\right)\end{array}$} \\
\hline & & Range & Mean & $\overline{\text { SD }}$ & Range & Mean & $\overline{\text { SD }}$ \\
\hline Cucumber & 41 & $0.17-1.62$ & $0.69 \mathrm{a}$ & 0.42 & $0.01-0.18$ & $0.07 \mathrm{a}$ & 0.04 \\
\hline Tomato & 39 & $0.08-1.42$ & $0.66 \mathrm{a}$ & 0.35 & $0.01-0.17$ & $0.07 \mathrm{a}$ & 0.04 \\
\hline Grape & 34 & $0.24-1.50$ & $0.72 \mathrm{a}$ & 0.37 & $0.01-0.17$ & $0.06 \mathrm{a}$ & 0.04 \\
\hline Strawberry & 45 & $0.13-1.28$ & $0.67 \mathrm{a}$ & 0.31 & $0.02-0.18$ & $0.08 \mathrm{a}$ & 0.05 \\
\hline
\end{tabular}

${ }^{x}$ Isolates were collected in approximately 40 commercial greenhouses in 11 geographic districts, including Jinan, Liaocheng, Tai'an, Zibo, Weifang, Binzhou, Jining, Dezhou, Laiwu, Heze, and Linyi of Shandong Province, China in 2010 and 2011. The four crops were cucumber, tomato, grape, and strawberry.

y $\mathrm{EC}_{50}$ values are the effective concentrations of fungicide that inhibited mycelium growth on potato dextrose medium or conidium germination on yeast-peptone-acetate medium by $50 \%$. Mean values followed by the same letter in the columns were not found to be significantly different by Fisher's least significant difference test at $P=0.05$. SD $=$ standard deviation.

z Number of isolates. fluopyram, diethofencarb, iprodione, pyrimethanil, and SYP-Z048. The $\mathrm{EC}_{50}$ values were transformed to $\log _{10}$ values, and Pearson correlation coefficients $(r)$ were calculated using SAS. CE data were arcsine square-root transformed prior to statistical analysis. To detect differences between treatments, $\mathrm{EC}_{50}$ values and $\mathrm{CE}$ were assessed using a one-way analysis of variance, and means were compared with Fisher's least significant difference test $(P=0.05)$.

\section{Results}

Effects on mycelial growth, spore germination, and germtube elongation. The three $B$. cinerea isolates used in the present study showed similar biological responses to the same isopyrazam concentration and, therefore, data were combined. Mean values of inhibition caused by increasing concentrations of isopyrazam on mycelial growth, spore germination, and germ-tube elongation were subjected to probit analysis (Fig. 1), and the $\mathrm{EC}_{50}$ values ranged from 0.53 to $0.74,0.04$ to 0.07 , and 0.02 to $0.04 \mu \mathrm{g} \mathrm{ml} \mathrm{m}^{-1}$, respectively. Moreover, the inhibition rates of spore germination and germ-tube elongation were greater than $98 \%$ at a concentration of $0.6 \mu \mathrm{g} \mathrm{ml}^{-1}$. However, the inhibition of mycelial growth was approximately $85 \%$ at a concentration of $40 \mu \mathrm{g} \mathrm{ml}^{-1}$.

Baseline sensitivity to isopyrazam based on mycelial growth assay. In total, 159 single-spore isolates were assessed for sensitivity to isopyrazam based on mycelial growth. The mean $\mathrm{EC}_{50}$ values for $B$. cinerea collected from different crops were very similar. There was no significant difference in the mean $\mathrm{EC}_{50}$ value among cucumber, tomato, grape, and
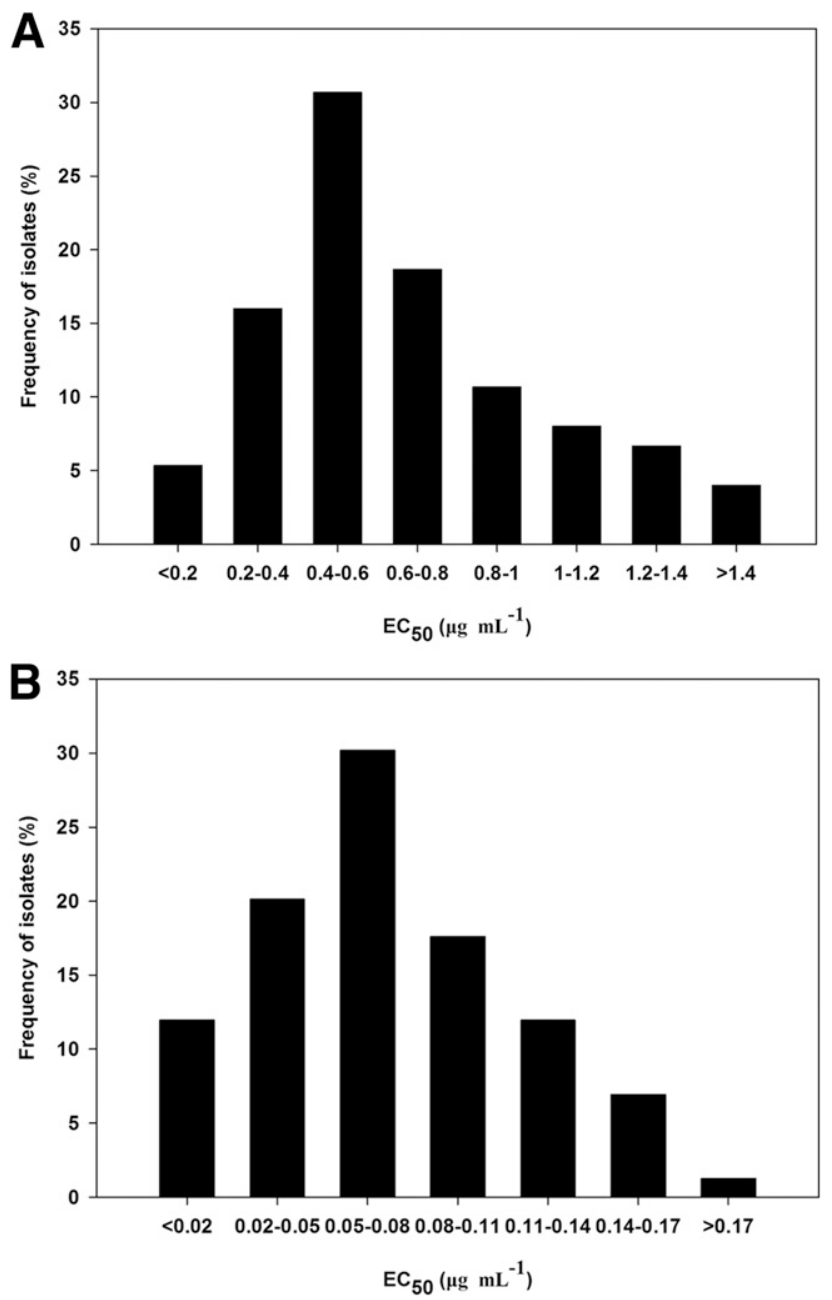

Fig. 2. Frequency distribution of $50 \%$ effective concentration $\left(E C_{50}\right)$ of 159 Botrytis cinerea isolates treated with isopyrazam based on $\mathbf{A}$, mycelial growth and $\mathbf{B}$, spore germination. $\mathrm{EC}_{50}$ values were calculated by performing a regression of the percent relative growth against the $\log _{10}$ fungicide concentration. 
strawberry (mean $\mathrm{EC}_{50}$ values of $0.69,0.66,0.72$, and $0.67 \mu \mathrm{g} \mathrm{ml}^{-1}$, respectively; $P>0.05$; Table 1 ).

Individual $\mathrm{EC}_{50}$ values for the 159 isolates were pooled to establish a sensitivity baseline for isolates from different crops. The frequency distribution of the $\mathrm{EC}_{50}$ values fit a unimodal curve (Fig. 2A). Values ranged from 0.08 to $1.62 \mu \mathrm{g} \mathrm{ml}^{-1}$, with a mean $\mathrm{EC}_{50}$ value of $0.68 \pm$ 0.36 (standard deviation) $\mu \mathrm{g} \mathrm{ml}^{-1}$. The variation factor (i.e., the highest $\mathrm{EC}_{50}$ value/the lowest $\mathrm{EC}_{50}$ value) was 20 .

Baseline sensitivity to isopyrazam on the inhibition of spore germination. The $159 \mathrm{~B}$. cinerea isolates were also assessed for sensitivity to isopyrazam on spore germination. There was no evident variation in the sensitivities of these isolates to isopyrazam $(P=0.05)$, and mean $\mathrm{EC}_{50}$ values of $0.07,0.07,0.06$, and $0.08 \mu \mathrm{g} \mathrm{ml}^{-1}$ were observed for the cucumber, tomato, grape, and strawberry populations, respectively (Table 1 ).

The frequency distribution of $\mathrm{EC}_{50}$ values for the 159 isolates was a unimodal curve (Fig. 2B) ranging from 0.01 to $0.18 \mu \mathrm{g} \mathrm{ml}^{-1}$, with a mean value of $0.07 \pm 0.04 \mu \mathrm{g} \mathrm{ml}^{-1}$ and a variation factor of 18 .

Correlation of $B$. cinerea sensitivity to isopyrazam and other botryticides. Isopyrazam sensitivity was plotted against sensitivity to boscalid, fluopyram, diethofencarb, iprodione, pyrimethanil, and SYP-Z048. Regression analyses and Pearson correlations were used to test the log-transformed $\mathrm{EC}_{50}$ values (Fig. 3). For the isopyrazam combinations tested, correlation coefficients ranged from -0.03 to $0.19(P>0.05)$. Thus, there was no significant correlation between isopyrazam sensitivity and sensitivity to other botryticides tested in this study.

Preventative and curative activity of isopyrazam. The protective efficacy of isopyrazam increased significantly $(P<0.05)$ with increasing concentration. At the highest tested concentration of isopyrazam (i.e., $200 \mu \mathrm{g} \mathrm{ml}^{-1}$ ), the efficacy of its protective activity ranged from 82.7 to $92.7 \%$ when the application was performed 96 and $24 \mathrm{~h}$ before inoculation, respectively (Table 2). The CE of samples treated with fluopyram was similar to that observed on fruit treated with isopyrazam at 150 and $200 \mu \mathrm{g} \mathrm{ml}^{-1}$ when the application was carried out either 24 or $48 \mathrm{~h}$ preinoculation. Moreover, the application of isopyrazam at $100 \mu \mathrm{g} \mathrm{ml}^{-1}$ also provided good CE that did not differ significantly compared with procymidone for all three applications (Table 2).

For the curative efficacy, the $\mathrm{CE}$ of isopyrazam in all experiments was greater than $60 \%$ when applied $24 \mathrm{~h}$ after inoculation (Table 2). However, postinoculation isopyrazam applications at lower concentrations resulted in lower CE when application was carried out either 48 or $96 \mathrm{~h}$ postinoculation.
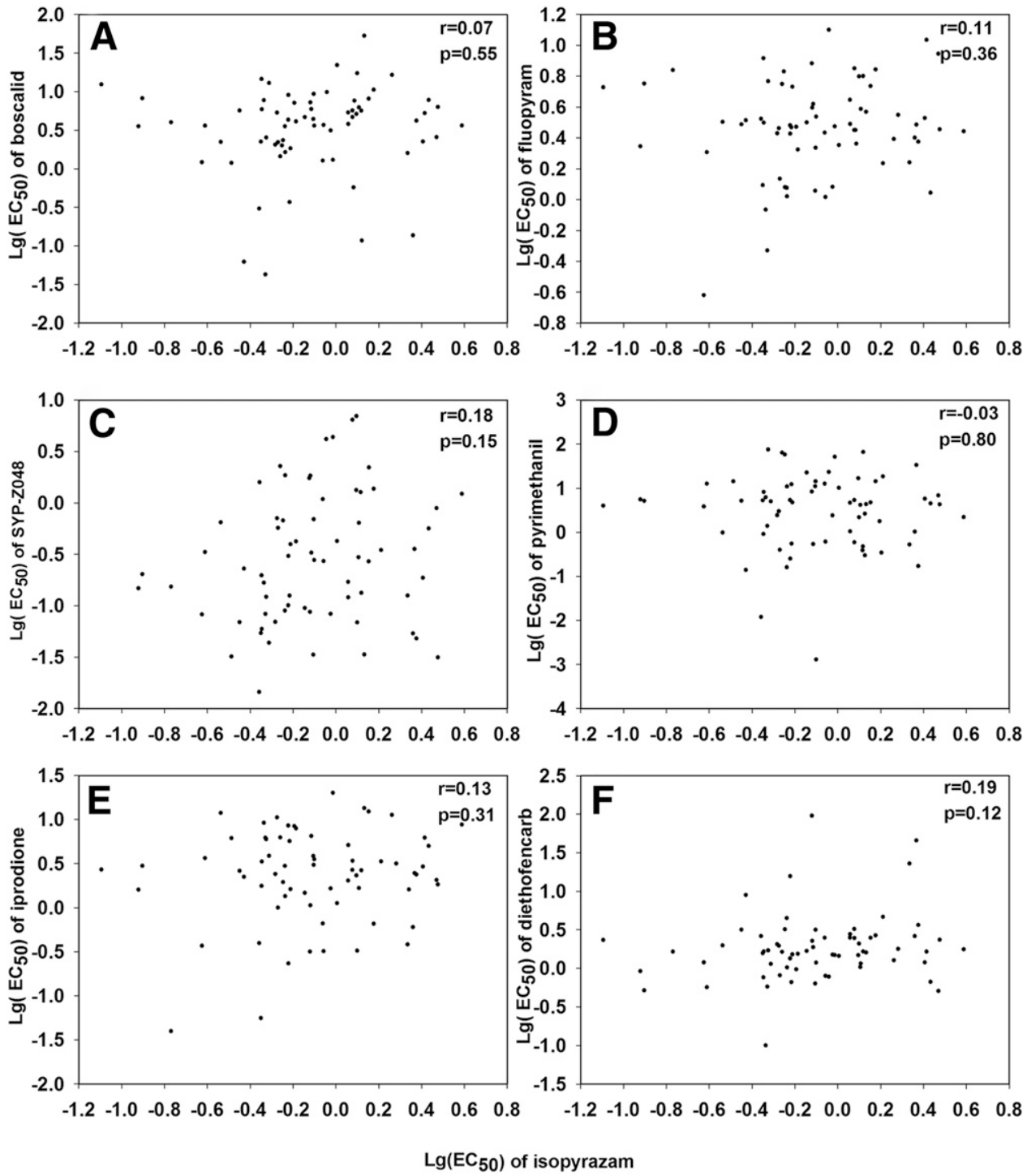

Fig. 3. Pearson correlation coefficients of sensitivity of 68 Botrytis cinerea isolates to isopyrazam and sensitivity to A, boscalid; B, fluopyram; C, SYP-Z048; D, pyrimethanil; E, iprodione; or F, diethofencarb. Sensitivity of 68 Botrytis cinerea to each fungicide was tested based on mycelial growth on potato dextrose agar media, and the $50 \%$ effective concentration $\left(\mathrm{EC}_{50}\right)$ values were transformed to $\log _{10}$ values. Sensitivity to isopyrazam was plotted against the sensitivity to six other fungicides. 
Field trial. In all experiments conducted during 2014 and 2015, isopyrazam and the commercial fungicides produced a marked reduction in the severity of gray mold disease, and the CE increased significantly as the isopyrazam dose increased from 100 to $200 \mathrm{~g}$ a.i. ha ${ }^{-1}$ (Table 3). From 2014 to 2015 , the highest dose of isopyrazam treatment achieved the best efficacy, ranging from 83.3 to $87.8 \%$ on leaves and 86.4 to $90.7 \%$ on fruit. Moreover, no significant differences were found in CE between isopyrazam at a low dose and procymidone on either leaves or fruit over 2 years. This indicates that isopyrazam succeeded in controlling gray mold at all doses.

\section{Discussion}

This study suggests that isopyrazam is highly effective at repressing the mycelial growth, spore germination, and germ-tube elongation of $B$. cinerea. Moreover, spore germination and germ-tube elongation were completely inhibited at a very low concentration of $1 \mu \mathrm{g} \mathrm{ml}^{-1}$ on YBA medium. The effect of isopyrazam on spore germination can probably be explained by the fact that germinating fungal spores respire actively, because this is a fungal developmental stage highly demanding in energy (Allen 1965). Furthermore, the strong inhibition of $B$. cinerea spore germination and germ-tube elongation have also been reported with other SDHI fungicides such as fluopyram and boscalid, which have a similar mode of action (De Miccolis Angelini et al. 2010; Veloukas et al. 2013; Weber 2011). The mycelial growth of $B$. cinerea was completely inhibited at a concentration of isopyrazam at $10 \mu \mathrm{g} \mathrm{ml}^{-1}$ on YBA medium and $50 \mu \mathrm{g} \mathrm{ml}^{-1}$ on PDA medium. Veloukas and Karaoglanidis (2012) found that the completely inhibited concentration of fluopyram on B. cinerea spore germination was lower than mycelial growth on YBA medium; however, fluopyram failed to completely inhibit the mycelial growth of $B$. cinerea at the concentration of $10 \mu \mathrm{g} \mathrm{ml}^{-1}$ on PDA.

The effects of isopyrazam on mycelial growth and spore germination were consistent with its preventive and curative activity against
B. cinerea on strawberry fruit and its high CE against gray mold on cucumber in field trials conducted during 2014 and 2015. There was no significant difference between reference fungicides procymidone and isopyrazam at $100 \mu \mathrm{g} \mathrm{ml}^{-1}$ before inoculation $(P>0.05)$. However, the CE of procymidone was significantly higher than that of isopyrazam at $100 \mu \mathrm{g} \mathrm{ml}^{-1}$ when applied postinoculation. This finding suggests that isopyrazam at $100 \mu \mathrm{g} \mathrm{ml}^{-1}$ provides lower curative activity but higher or similar preventative activity against $B$. cinerea compared with procymidone. The CE of isopyrazam at 150 and $200 \mu \mathrm{g} \mathrm{ml}^{-1}$ were similar to that of fluopyram when applied either pre- or postinoculation or during the field trails. This demonstrated that isopyrazam at high concentrations not only exhibited effective preventive activity but also exhibited satisfactory curative activity. However, isopyrazam should be used preventively or at the early stage of disease infection to reduce the chance of contacting the pathogen; postinfection applications of isopyrazam may accelerate the development of resistance. In spite of its high efficacy, isopyrazam has not been registered for controlling $B$. cinerea in China. Thus, isopyrazam has the potential to be an excellent alternative fungicide for the control of gray mold.

Establishment of a sensitivity baseline is of great importance for detecting subsequent changes in pathogen sensitivity or the development of resistance, as well as for the future management of fungicide resistance. Thus, prior to introducing a new fungicide into the market, the establishment of baseline sensitivity is of vital importance (Russell 2004). In the current study, the sensitivity of 159 singlespore isolates of $B$. cinerea to isopyrazam was tested based on mycelial growth and spore germination. The baseline sensitivity curves for isopyrazam were both unimodal in pathogen populations that had never been exposed to SDHI fungicides, which suggested that there were no resistant subpopulations among the isolates tested in this study (Li et al. 2014). Therefore, these data can be used as a baseline to monitor changes in the sensitivity of $B$. cinerea populations to

Table 2. Protective and curative activity of isopyrazam against Botrytis cinerea on detached strawberry fruit ${ }^{\mathrm{w}}$

\begin{tabular}{|c|c|c|c|c|c|c|c|}
\hline \multirow[b]{2}{*}{ Treatment $^{\mathrm{x}}$} & \multirow[b]{2}{*}{$\mathrm{EC}\left(\mu \mathrm{g} \mathrm{ml}^{-1}\right)^{\mathrm{y}}$} & \multicolumn{3}{|c|}{ Protective CE (\%) } & \multicolumn{3}{|c|}{ Curative CE (\%) } \\
\hline & & $96 h^{z}$ & $48 \mathrm{~h}$ & $24 \mathrm{~h}$ & $24 \mathrm{~h}$ & $48 \mathrm{~h}$ & $96 \mathrm{~h}$ \\
\hline \multirow[t]{4}{*}{ Isopyrazam } & 50 & $49.6 \mathrm{~d}$ & $55.8 \mathrm{~d}$ & $66.6 \mathrm{~d}$ & $69.6 \mathrm{e}$ & $50.7 \mathrm{e}$ & $31.4 \mathrm{e}$ \\
\hline & 100 & $65.0 \mathrm{bc}$ & $78.4 \mathrm{c}$ & $84.6 \mathrm{c}$ & $78.5 \mathrm{~d}$ & $57.3 \mathrm{~d}$ & $46.4 \mathrm{~d}$ \\
\hline & 150 & $71.3 \mathrm{~b}$ & $83.1 \mathrm{~b}$ & $89.5 \mathrm{ab}$ & $86.9 \mathrm{bc}$ & $77.6 \mathrm{~b}$ & $69.0 \mathrm{~b}$ \\
\hline & 200 & $82.7 \mathrm{a}$ & $87.1 \mathrm{a}$ & $92.7 \mathrm{a}$ & $90.6 \mathrm{a}$ & $81.1 \mathrm{a}$ & $73.1 \mathrm{a}$ \\
\hline Fluopyram & 80 & $81.1 \mathrm{a}$ & $85.2 \mathrm{ab}$ & $91.1 \mathrm{a}$ & $89.8 \mathrm{ab}$ & $80.4 \mathrm{ab}$ & $69.5 \mathrm{~b}$ \\
\hline Procymidone & 600 & $58.5 \mathrm{c}$ & $76.4 \mathrm{c}$ & $87.4 \mathrm{bc}$ & $85.8 \mathrm{c}$ & $73.7 \mathrm{c}$ & $52.1 \mathrm{c}$ \\
\hline
\end{tabular}

${ }^{\mathrm{w}}$ Experiments were performed in the lab in 2014. Mean values followed by the same letter in the columns were not significantly different according to Fisher's least significant difference test at $P=0.05$. CE $=$ control efficacy.

${ }^{x}$ Each treatment was sprayed until runoff with a hand-held sprayer and air dried for $1 \mathrm{~h}$.

y Effective concentrations of fungicide (dose) that inhibited mycelium growth.

$\mathrm{z}$ For protective treatments, fungicides were sprayed $96 \mathrm{~h}$ prior to inoculation.

Table 3. Efficacy of isopyrazam for suppression of gray mold in greenhouse-grown 'Xintai Mici' cucumber ${ }^{y}$

\begin{tabular}{|c|c|c|c|c|c|c|c|c|c|c|c|c|c|}
\hline \multirow[b]{4}{*}{ Fungicides } & \multirow[b]{4}{*}{ EC $\left(\mathrm{g} \mathrm{ha}^{-1}\right)^{\mathrm{z}}$} & \multicolumn{6}{|c|}{2014} & \multicolumn{6}{|c|}{2015} \\
\hline & & \multicolumn{2}{|c|}{$\begin{array}{c}\text { Before } \\
\text { treatment }\end{array}$} & \multicolumn{4}{|c|}{7 days after last treatment } & \multicolumn{2}{|c|}{$\begin{array}{c}\text { Before } \\
\text { treatment }\end{array}$} & \multicolumn{4}{|c|}{7 days after last treatment } \\
\hline & & \multirow{2}{*}{$\frac{\mathrm{DI}}{\mathrm{L}}$} & \multirow{2}{*}{$\frac{\mathrm{DR}}{\mathrm{F}}$} & \multirow{2}{*}{$\frac{\overline{D I}}{\mathrm{~L}}$} & \multirow{2}{*}{$\frac{\text { DR }}{F}$} & \multicolumn{2}{|c|}{$\mathrm{CE}(\%)$} & \multirow{2}{*}{$\frac{\overline{D I}}{\mathrm{~L}}$} & \multirow{2}{*}{$\frac{\text { DR }}{\mathbf{F}}$} & \multirow{2}{*}{$\frac{\mathrm{DI}}{\mathrm{L}}$} & \multirow{2}{*}{$\frac{\text { DR }}{\mathbf{F}}$} & \multicolumn{2}{|c|}{ CE $(\%)$} \\
\hline & & & & & & $\mathbf{L}$ & $\mathbf{F}$ & & & & & $\mathbf{L}$ & $\mathbf{F}$ \\
\hline \multirow[t]{3}{*}{ Isopyrazam (EC) $125 \mathrm{~g} \mathrm{liter}^{-1}$} & 100 & 1.9 & 6.4 & 3.6 & 6.1 & $69.7 \mathrm{~d}$ & $75.1 \mathrm{c}$ & 1.0 & 3.3 & 2.4 & 4.0 & $73.8 \mathrm{~b}$ & $\overline{79.9 \mathrm{a}}$ \\
\hline & 150 & 2.2 & 6.4 & 3.0 & 4.7 & $76.7 \mathrm{bc}$ & $81.5 \mathrm{abc}$ & 0.8 & 3.2 & 1.4 & 2.9 & $80.2 \mathrm{~b}$ & $84.0 \mathrm{a}$ \\
\hline & 200 & 2.1 & 6.2 & 2.1 & 3.1 & $83.3 \mathrm{a}$ & $86.4 \mathrm{a}$ & 1.2 & 3.1 & 1.2 & 1.5 & $87.8 \mathrm{a}$ & $90.7 \mathrm{a}$ \\
\hline Fluopyram (SC) 41.7\% & 100 & 2.0 & 6.3 & 2.4 & 4.0 & $80.2 \mathrm{ab}$ & $84.1 \mathrm{ab}$ & 1.0 & 3.3 & 1.7 & 2.3 & $82.1 \mathrm{ab}$ & $88.9 \mathrm{a}$ \\
\hline Procymidone (WP) $50 \%$ & 600 & 1.9 & 6.0 & 3.3 & 5.3 & $72.4 \mathrm{~cd}$ & $77.1 \mathrm{bc}$ & 1.2 & 3.0 & 2.4 & 2.6 & $78.3 \mathrm{~b}$ & $85.1 \mathrm{a}$ \\
\hline Water control & - & 2.0 & 6.1 & 12.1 & 23.8 & - & - & 1.1 & 3.3 & 10.0 & 19.0 & - & - \\
\hline
\end{tabular}

y Experiments were performed in Tai' an City in Shandong Province in 2014 and 2015. DI $=$ disease index, DR $=$ disease rate, $\mathrm{CE}=$ control efficacy, $\mathrm{L}=$ leaf, and $\mathrm{F}=$ fruit. Mean values followed by the same letter in the columns were not significantly different according to Fisher's least significant difference test at $P=0.05$.

${ }^{\mathrm{z}}$ Effective concentration (dose) of active ingredient. The volume of fungicide applied was 750 liters/ha. The sprayer used in the experiment was the universal MATABI-16 knapsack hand sprayer, and the pressure on the sprayer was set to $0.3 \mathrm{MPa}$. Fungicides were sprayed three times at 7-day intervals. 
isopyrazam (Russell 2004). The variation factors of spore germination and mycelial growth were both less than 20 , indicating a low variation in sensitivity among isolates. In addition, the factors of $B$. cinerea spore germination and mycelial growth to boscalid were 41 and 84, respectively (Zhang et al. 2007). However, the narrow sensitivity range did not suggest that the pathogen has less potential for developing resistance (Mamiev et al. 2013).

Currently, there are several articles reporting the development of resistance in $B$. cinerea to boscalid and fluopyram in different countries (Amiri et al. 2014; Bardas et al. 2010; Yu et al. 2012; Zhang et al. 2015). Veloukas et al. (2013) also reported that there was crossresistance between boscalid and isopyrazam in H272R (replacements of histidine by arginine) or H272Y (replacements of histidine by tyrosine) mutants, which were the most frequent genotypes detected in SDHI-resistant field strains of B. cinerea (Yin et al. 2011). However, we observed there was no correlation between isopyrazam and boscalid in our study. This result can probably be explained by the fact that, within the 68 isolates tested, there were no moderate or high levels of resistance to boscalid, and the isolates may not possess the H272R or H272Y mutants, which still need further study. Interestingly, there was no cross-resistance between fluopyram and isopyrazam or boscalid in H272R or H272Y mutants (Veloukas et al. 2013). A similar absence of cross-resistance between boscalid and fluopyram has been found for Alternaria alternata (Avenot and Michailides 2010), B. cinerea (Veloukas and Karaoglanidis 2012), Corynespora cassisicola, and Podosphaera xanthii (Ishii et al. 2011). In our study, we also found that there was no correlation between isopyrazam and fluopyram, although the 68 isolates tested were just sensitive and had low levels of resistance to fluopyram. In addition, the cross-resistance between isopyrazam and boscalid or fluopyram will need further study. The 68 isolates exhibited several levels of sensitivity to diethofencarb, iprodione, pyrimethanil, and SYP-Z048, including moderate or high levels of resistance. Furthermore, sensitivities to the four fungicides were not correlated, suggesting an absence of any multiple resistance relationship. Isopyrazam might be used as an alternative fungicide or in tank mixtures with these compounds other than SDHI to manage resistance.

To our knowledge, the current study is the first report of the baseline sensitivity of $B$. cinerea to isopyrazam in China and of the excellent efficacy of this fungicide in controlling gray mold. Taken together, isopyrazam, a new generation SDHI fungicide, is an excellent alternative for use in $B$. cinerea control programs. However, to avoid the development of resistance to isopyrazam, further study should be undertaken to select the most effective partners for use in mixtures.

\section{Acknowledgments}

This study was supported by the Research Award Fund for Excellent Young Scientists of Shandong Province (BS2011NY012).

\section{Literature Cited}

Ajigboye, O. O., Murchie, E., and Ray, R. V. 2014. Foliar application of isopyrazam and epoxiconazole improves photosystem II efficiency, biomass and yield in winter wheat. Pestic. Biochem. Physiol. 114:52-60.

Allen, P. J. 1965. Metabolic aspects of spore germination in fungi. Annu. Rev. Phytopathol. 3:313-342.

Amiri, A., Heath, S. M., and Peres, N. A. 2013. Phenotypic characterization of multifungicide resistance in Botrytis cinerea isolates from strawberry fields in Florida. Plant Dis. 97:393-401.

Amiri, A., Heath, S. M., and Peres, N. A. 2014. Resistance to fluopyram, fluxapyroxad, and penthiopyrad in Botrytis cinerea from strawberry. Plant Dis. 98:532-539.

De Miccolis Angelini, R. M., Habib, W., Rotolo, C., Pollastro, S., and Faretra, F. 2010. Selection, characterization and genetic analysis of laboratory mutants of Botryotinia fuckeliana (Botrytis cinerea) resistant to the fungicide boscalid. Eur. J. Plant Pathol. 128:185-199.

Avenot, H. F., and Michailides, T. J. 2010. Progress in understanding molecular mechanisms and evolution of resistance to succinate dehydrogenase inhibiting (SDHI) fungicides in phytopathogenic fungi. Crop Prot. 29:643-651.

Bardas, G. A., Veloukas, T., Koutita, O., and Karaoglanidis, G. S. 2010. Multiple resistance of Botrytis cinerea from kiwifruit to SDHIs, QoIs and fungicides of other chemical groups. Pest Manage. Sci. 66:967-973.

Brent, K. J., and Hollomon, D. W. 1998. Fungicide Resistance: The Assessment of Risk. FRAC Monograph No. 2. Global Crop Protection Federation, Brussels.
China Pesticide Information Network. 2014. Institute Control of Agrochemicals, Ministry of Agriculture, P. R. China. http://www.chinapesticide.gov. $\mathrm{cn} / \mathrm{sjzx} 4 \mathrm{ywb} /$ index.jhtml

Elad, Y., Williamson, B., Tudzynski, P., and Delen, N. 2004. Botrytis spp. and diseases they cause in agricultural systems-an introduction. Pages 1-8 in: Botrytis: Biology, Pathology and Control. Y. Elad, B. Williamson, P. Tudzynski, and N. Delen, eds. Springer, Dordrecht, The Netherlands.

Elad, Y., Yunis, H., and Katan, T. 1992. Multiple fungicide resistance to benzimidazoles, dicarboximides and diethofencarb in field isolates of Botrytis cinerea in Israel. Plant Pathol. 41:41-46.

Fernández-Ortuño, D., Chen, F., and Schnabel, G. 2012. Resistance to pyraclostrobin and boscalid in Botrytis cinerea isolates from strawberry fields in the Carolinas. Plant Dis. 96:1198-1203.

Fraaije, B. A., Bayon, C., Atkins, S., Cools, H. J., Lucas, J. A., and Fraaije, M. W. 2012. Risk assessment studies on succinate dehydrogenase inhibitors, the new weapons in the battle to control Septoria leaf blotch in wheat. Mol. Plant Pathol. 13:263-275.

Hägerhäll, C. 1997. Succinate: Quinone oxidoreductases: Variations on a conserved theme. Biochim. Biophys. Acta 1320:107-141.

Hammer, P. E., Evensen, K. B., and Janisiewicz, W. J. 1993. Postharvest control of Botrytis cinerea on cut rose flowers with pyrrolnitrin. Plant Dis. 77:283286

Harp, T. L., Godwin, J. R., Scalliet, G., Walter, H., Stalker, A. D., and Bartlett, D. W. 2011. Isopyrazam, a new generation cereal fungicide. Asp. Appl. Biol. 106:113-120.

Horsefield, R., Yankovskaya, V., Sexton, G., Whittingham, W., Shiomi, K., Ömura, S., and Iwata, S. 2006. Structural and computational analysis of the quinone-binding site of complex II (succinate-ubiquinone oxidoreductase): A mechanism of electron transfer and proton conduction during ubiquinone reduction. J. Biol. Chem. 281:7309-7316.

Ishii, H., Miyamoto, T., Ushio, S., and Kakishima, M. 2011. Lack of crossresistance to a novel succinate dehydrogenase inhibitor, fluopyram, in highly boscalid - resistant isolates of Corynespora cassiicola and Podosphaera xanthii. Pest Manage. Sci. 67:474-482.

Ito, Y., Muraguchi, H., Seshime, Y., Oita, S., and Yanagi, S. O. 2004. Flutolanil and carboxin resistance in Coprinus cinereus conferred by a mutation in the cytochrome b 560 subunit of succinate dehydrogenase complex (Complex II). Mol. Genet. Genomics 272:328-335.

Jarvis, W. R. 1977. Botryotinia and Botrytis Species: Taxonomy, Physiology and Pathogenicity. Monograph 15. Research Branch Canada, Department of Agriculture, Ottawa, ON, Canada.

Keon, J. P., White, G. A., and Hargreaves, J. A. 1991. Isolation, characterization and sequence of a gene conferring resistance to the systemic fungicide carboxin from the maize smut pathogen, Ustilago maydis. Curr. Genet. 19: 475-481.

Kerssies, A. 1993. Influence of environmental conditions on dispersal of Botrytis cinerea conidia and on post-harvest infection of gerbera flowers grown under glass. Plant Pathol. 42:754-762.

Leroux, P. 2007. Chemical control of Botrytis and its resistance to chemical fungicides. Pages 195-222 in: Botrytis: Biology, Pathology and Control. Y. Elad, B. Williamson, P. Tudzynski, and N. Delen, eds. Springer Verlag, Dordrecht, The Netherlands.

Li, S., Hou, Y., Peng, D., Meng, L., Wang, J., Zhou, M., and Chen, C. 2014 Baseline sensitivity and control efficacy of flutolanil in Rhizoctonia solani. Australas. Plant Pathol. 43:313-320.

Ma, J. Y., Zhang, X. F., Wang, W. Q., Han, X. Y., Ma, Z. Q., and Ding, H. B. 2009. The sensitivity of Botrytis cinerea to SYP-Z048 and cross resistance against diverse fungicides. Acta Phytophylac. Sin. 36:61-64.

Mamiev, M., Korolev, N., and Elad, Y. 2013. Resistance to polyoxin AL and other fungicides in Botrytis cinerea collected from sweet basil crops in Israel. Eur. J. Plant Pathol. 137:79-91.

Matsson, M., and Hederstedt, L. 2001. The carboxin-binding site on Paracoccus denitrificans succinate: Quinone reductase identified by mutations. J. Bioenerg. Biomembr. 33:99-105.

Miyamoto, T., Ishii, H., Stammler, G., Koch, A., Ogawara, T., Tomita, Y., and Kobori, S. 2010. Distribution and molecular characterization of Corynespora cassiicola isolates resistant to boscalid. Plant Pathol. 59:873-881.

Myresiotis, C. K., Karaoglanidis, G. S., and Tzavella-Klonari, K. 2007. Resistance of Botrytis cinerea isolates from vegetable crops to annilinopyrimidine, phenylpyrrole, hydroxyanilide, benzimidazole, and dicarboximide fungicides. Plant Dis. 91:407-413.

Rodríguez, A., Acosta, A., and Rodríguez, C. 2014. Fungicide resistance of Botrytis cinerea in tomato greenhouses in the Canary Islands and effectiveness of non-chemical treatments against gray mold. World. J. Microb. Biot. 30:23972406.

Russell, P. E. 2004. Sensitivity Baselines in Fungicide Resistance Research and Management. FRAC Monograph 3. Crop Life International, Brussels.

Sattler, U., Harp, T., Bartlett, D., and Godwin, J. 2010. Isopyrazam-A new drug for disease control in cereals. Julius Kühn Archiv. 428:90-91.

Shen, R. P., Song, Y. Y., Wang, Q. H., and Liu, F. 2014. Compare of fungistasis of two new succinate dehydrogenase inhibitor. Pestic. Sci. Adm. 8:52-57.

Stammler, G., and Speakman, J. 2006. Microtiter method to test the sensitivity of Botrytis cinerea to boscalid. J. Phytopathol. 154:508-510. 
Standards Press of China. 2000. Guidelines for the field efficacy trials-Fungicides against gray mold of vegetables: GB/T 17980.28-2000. Pesticide-Guidelines for the field efficacy trials. Standards Press of China, Beijing.

Veloukas, T., and Karaoglanidis, G. S. 2012. Biological activity of the succinate dehydrogenase inhibitor fluopyram against Botrytis cinerea and fungal baseline sensitivity. Pest Manage. Sci. 68:858-864.

Veloukas, T., Markoglou, A. N., and Karaoglanidis, G. S. 2013. Differential effect of $s d h \mathrm{~B}$ gene mutations on the sensitivity to SDHI fungicides in Botrytis cinerea. Plant Dis. 97:118-122.

Weber, R. W. S. 2011. Resistance of Botrytis cinerea to multiple fungicides in northern German small-fruit production. Plant Dis. 95:1263-1269.

Williamson, B., Tudzynski, B., Tudzynski, P., and Van Kan, J. A. L. 2007. Botrytis cinerea: The cause of grey mould disease. Mol. Plant Pathol. 8:561-580.

Yang, Y. T. 2003. Advance in research of epidemiology and control strategies for grey mould disease in China. Chin. J. Pestic. Sci. 42:6-9.
Yin, Y. N., Kim, Y. K., and Xiao, C. L. 2011. Molecular characterization of boscalid resistance in field isolates of Botrytis cinerea from apple. Phytopathology 101:986-995.

Yu, L., Liu, H. P., Han, J. C., and Zhang, B. J. 2012. Sensitivity of Botrytis cinerea from Shanxi Province to boscalid. J. Shanxi Agric. Univ. 03:232-234.

Zhang, C. Q., Hu, J. L., Wei, F. L., and Zhu, G. N. 2009. Evolution of resistance to different classes of fungicides in Botrytis cinerea from greenhouse vegetables in eastern China. Phytoparasitica 37:351-359.

Zhang, C. Q., Yuan, S. K., Sun, H. Y., Qi, Z. Q., Zhou, M. G., and Zhu, G. N. 2007. Sensitivity of Botrytis cinerea from vegetable greenhouses to boscalid. Plant Pathol. 56:646-653.

Zhang, X. K., Han, X., Ma, W., Zhang, X., Zhang, X. R., Duan, Y. B., Zhou, M. G., and Chen, C. J. 2015. Baseline sensitivity of fluopyram and its resistance risk assessment against Botrytis cinerea from strawberry in Jiangsu province. J. Nanjing Agric. Univ. 38:810-815. 